\title{
A Solid-Phase Extraction Method for Analyzing Trace Amounts of Polychlorinated Dibenzo-p-Dioxins and Dibenzofurans in Waste Water
}

\author{
Deok-Hie Park ${ }^{\mathrm{a}}$, Yeu Young Youn ${ }^{\mathrm{a}}$, Jaewon Choi ${ }^{\mathrm{b}}$, Young-Hee Lim ${ }^{\mathrm{a}}$, and Hye-Sung Cho ${ }^{\mathrm{a}, *}$ \\ ${ }^{a}$ LG Chem. Ltd/Research Park, 104-1 Moonji-dong, Yuseong-gu, Daejeon 305-380, Korea \\ ${ }^{b}$ Water Analysis \& Research Center, K-water, 6-2 San, Yeonchuk-dong, Daeduck-gu, Daejeon 306-711, Korea
}

Received February 21, 2011; Revised March 7, 2011; Accepted March 7, 2011

First published on the web March 15, 2011; DOI: 10.5478/MSL.2011.2.1.012

\begin{abstract}
The Korean government has regulated emission of polychlorinated dibenzo- $p$-dioxins and dibenzofurans (PCDD/Fs) in waste water of manufacturing facilities producing chlorinated compounds since 2009 . As this regulation is expected to be reinforced in 2013 to $50 \mathrm{pg} \mathrm{I-TEQ/L,} \mathrm{a} \mathrm{large} \mathrm{sample} \mathrm{volume} \mathrm{is} \mathrm{required} \mathrm{for} \mathrm{the} \mathrm{analysis} \mathrm{of} \mathrm{trace} \mathrm{amounts} \mathrm{of} \mathrm{PCDD/Fs} \mathrm{in} \mathrm{waste}$ water. Liquid-liquid extraction (LLE) is used to extract PCDD/Fs from aqueous samples; however, its low efficiency makes it inadequate for analyzing large sample volumes. Herein, we present a disk-type solid-phase extraction (SPE) method for the analysis of dioxin at a part per quadrillion level in waste water. This SPE system contains airtight glass covers with a decompression pump, which enables continuous semi-automated extraction. Small $(0.5 \mathrm{~L})$ and large $(7 \mathrm{~L})$ samples were extracted using LLE and SPE methods, respectively. The method detection limits (MDLs) were 0.001-0.25 and 0.015-4.1 pg I-TEQ/L for the SPE and LLE methods, respectively. The concentrations of detected congeners with both methods were similar. However, the concentrations of several congeners that were not detected with the LLE method were quantified using the SPE method.
\end{abstract}

Key words: PCDD/F, Waste water, Solid-phase extraction, Method Detection Limit (MDL)

\section{Introduction}

Polychlorinated dibenzo- $p$-dioxins and dibenzofurans (PCDD/Fs) are among the most toxic chemicals known, with carcinogenic, immunotoxic, reproductive, and developmental effects in mammals, including interference with regulatory hormones in humans. ${ }^{1-6} \mathrm{PCDD} /$ Fs are formed as unintentional byproducts during incineration, chlorinated compound production, and industrial thermal processes. ${ }^{7-9}$ The Stockholm convention (2005), an international treaty, banned persistent organic pollutants, including PCDD/Fs. Since ratifying the Stockholm convention, the Korean government has regulated $\mathrm{PCDD} / \mathrm{Fs}$ in the effluent of manufacturing facilities producing chlorinated compounds ${ }^{10}$ and has lowered the limits set in this regulation from $300 \mathrm{pg}$ I-TEQ/L in 2009 to $50 \mathrm{pg} \mathrm{I-TEQ/L}$ in 2013. Given the extremely low emitted concentrations of $\mathrm{PCDD} / \mathrm{Fs}$, which are in the range of parts per quadrillion (ppq), a low detection limit is required for accurate analyses. This implies that a large sample volume is required for PCDD/Fs analysis. ${ }^{11-12}$ Liquid-liquid extraction (LLE) has been used widely to extract PCDD/Fs from aqueous samples. ${ }^{13-14}$ However, it is inadequate for analyzing large sample volumes because of its low efficiency and the need for large amounts of organic solvents and several immersions, which lead to low recoveries. A more efficient system is required for analyzing PCDD/Fs

*Reprint requests to Dr. Hye-Sung Cho

E-mail: hschoc@Igchem.com in large aqueous samples. Recently, it has been shown that an octadecyl (C18) disk with an i.d. of $90 \mathrm{~mm}$ in a semi-automated solid-phase extraction (SPE) system can be used to extract PCDD/Fs from water samples of up to 40 L. ${ }^{15-16}$ This system has been tested for the analysis of PCDD/Fs in effluent samples.

The present study validated the new semi-automated SPE system by measuring the recoveries and comparing them with those of an LLE system. The method detection limits (MDLs) and the concentrations according to the sample volume were also compared between the SPE and LLE systems.

\section{Experimental}

\section{Reagents and standards}

Hexane, toluene, dichloromethane, acetone, and methanol of high-performance liquid chromatography grade were obtained from J.T. Baker (Phillipsburg, NJ, USA). $n$-Nonane of $99 \%$ purity was purchased from Acros Organics (Geel, Belgium). A cleanup standard $\left({ }^{37} \mathrm{Cl}_{4}-2,3,7,8-\mathrm{TCDD}\right)$ was from Wellington Laboratories (Toronto, Canada). The calibration standard and internal standard were from Cambridge Isotope Laboratories (Andover, MA, USA). Sodium sulfate was obtained from Kanto (Tokyo, Japan). Multilayer silica gel and basic alumina for column chromatography were obtained from Wako (Osaka, Japan) and Sigma-Aldrich (Milwaukee, WI, USA).

\section{Semi-automated disk-type SPE system}

Empore $\mathrm{C} 18$ disks (i.d., $90 \mathrm{~mm}$; thickness, $0.5 \mathrm{~mm}$; capacity, $70 \mathrm{mg}$ ) and a glass fiber filter (GFF; i.d., $90 \mathrm{~mm}$; pore size, 
$0.7 \mu \mathrm{m}$ ) were purchased from $3 \mathrm{M}$ (St. Paul, Minnesota, USA) and Whatman (Maidstone, Kent, UK), respectively. The semiautomated SPE system was from GL Science (Tokyo, Japan). This system can continuously extract an aqueous sample at a maximum flow rate of $200 \mathrm{~mL} / \mathrm{min}^{16}$

\section{Sample preparation}

Samples of 17 toxic 2,3,7,8-substituted PCDD/F congeners were prepared according to the Official Method for PCDD/Fs in Waste Water-HRGC/HRMS (2007), which is a modified extraction procedure. After adding ${ }^{13} \mathrm{C}_{12}$-labeled PCDD/F internal standards, a $0.5-\mathrm{L}$ sample was extracted in a funnel with hexane using the LLE method, and a 7-L sample was extracted using disk-type SPE and Soxhlet methods. The samples were cleaned on a multi-silica and alumina column. Finally, ${ }^{13} \mathrm{C}_{12}$-labeled PCDD/F injection standards were added to the concentrated samples under a stream $\mathrm{N}_{2}$ gas before analysis. The toxic equivalent concentration (TEQ) was calculated using international toxicity equivalence factors (TEFs). ${ }^{17}$

\section{Instrumental analysis}

The PCDD/Fs were analyzed using GC-HRMS in multi-ion detection mode (MID; the same as selected ion monitoring, or SIM) using a Trace GC ultra-gas chromatograph coupled to a DFS (Thermo Scientific, Germany) and equipped with an SP-2331 capillary column $(60 \mathrm{~m} \times 0.32 \mathrm{~mm}, 0.2 \mu \mathrm{m})$. The HRMS system was operated in electron impact ionization mode $(40 \mathrm{eV})$ at a resolution of $\mathrm{R}>10,000$ (10\% valley) (Table 1$)$.

\section{Results and Discussion}

\section{Determination of the method detection limits}

The procedure for determining the MDLs followed the Japanese Industrial Standards (JIS) K0312 method. ${ }^{18}$ We prepared five water blanks that were as free of analytes as

Table 1. The experimental conditions used for GC-HRMS.

\begin{tabular}{|c|c|c|}
\hline \multirow{5}{*}{ GC } & Injection mode & Splitless \\
\hline & Injector temp. & $260^{\circ} \mathrm{C}$ \\
\hline & Carrier gas & $\mathrm{He}, 0.8 \mathrm{~mL} / \mathrm{min}$ \\
\hline & Column & $\begin{array}{l}\text { SP-2331 : Cyanopropyl polysiloxane } \\
60 \mathrm{~m} \text { (length) } \times 0.32 \mathrm{~mm} \text { (i.d.) } \times 0.2 \mu \mathrm{m} \\
\text { (film thickness) }\end{array}$ \\
\hline & $\begin{array}{l}\text { Temperature } \\
\text { program }\end{array}$ & $\begin{array}{l}\mathrm{SP}-2331: 120^{\circ} \mathrm{C}(3 \mathrm{~min})-20^{\circ} \mathrm{C} / \mathrm{min}-220^{\circ} \mathrm{C} \\
(0 \mathrm{~min})-4^{\circ} \mathrm{C} / \mathrm{min}-260^{\circ} \mathrm{C}(32 \mathrm{~min})\end{array}$ \\
\hline \multirow{6}{*}{ MS } & Ionization mode & Electron impact (EI) \\
\hline & Ionizing current & $0.6 \mathrm{~mA}$ \\
\hline & Detection mode & Selected ion monitoring (SIM) \\
\hline & Electron energy & $40 \mathrm{eV}$ \\
\hline & Accel. voltage & $4 \mathrm{kV}$ \\
\hline & Resolution & $>10,000(10 \%$ valley $)$ \\
\hline
\end{tabular}

possible to check the blank levels of the 17 congeners using each method. For a few analytes $(1,2,3,4,6,7,8-\mathrm{HpCDF}$ and OCDF in the LLE method and OCDD and OCDF in the SPE method), background contamination was detected. Standard deviations of the detected background concentrations were used in determining the MDL. To calculate the MDL, seven samples spiked with $30 \mu \mathrm{l}$ of CS1 standard were processed using both analytical methods (LLE and SPE), and the samples were analyzed using GC-HRMS to determine the standard deviations of the quantified concentrations. Detection limit (DL) was defined as three times the standard deviation. The MDL was determined using the following equation; ${ }^{18}$

$$
M D L=D L \times \frac{v}{v_{1}} \times \frac{V_{E}}{V_{E}^{\prime}} \times \frac{1}{V}
$$

Where,

DL : Detection limit (pg)

$v:$ Final concentrated sample volume $(\mu \mathrm{L})$

$v_{l}:$ Injection volume $(\mu \mathrm{L})$

$V_{E}$ : Extraction volume $(\mathrm{mL})$

$V_{E}^{\prime}$ : Aliquots of extraction volume $(\mathrm{mL})$

$\mathrm{V}$ : Sample volume (L)

The MDLs were compared between the SPE and LLE methods (Table 2). The MDLs ranged from 0.001 to $0.25 \mathrm{pg} \mathrm{I-TEQ/L}$ for the SPE method and from 0.015 to $4.1 \mathrm{pg} \mathrm{I-TEQ/L} \mathrm{for}$

Table 2. The determined method detection limits for seventeen 2,3,7,8-substituted PCDD/Fs according to the sample volume.

\begin{tabular}{|c|c|c|}
\hline \multirow{2}{*}{ Congeners } & \multicolumn{2}{|c|}{ MDL (pg I-TEQ/L) } \\
\hline & $0.5 \mathrm{~L}$ (LLE method) & $7 \mathrm{~L}$ (SPE method) \\
\hline 2378-TeCDD & 3.5 & 0.18 \\
\hline 12378-PeCDD & 4.1 & 0.14 \\
\hline 123478-HxCDD & 0.65 & 0.098 \\
\hline 123678-HxCDD & 0.88 & 0.055 \\
\hline 123789-HxCDD & 0.71 & 0.096 \\
\hline 1234678-HpCDD & 0.13 & 0.017 \\
\hline OCDD & 0.015 & 0.001 \\
\hline 2378-TeCDF & 0.35 & 0.017 \\
\hline 12378-PeCDF & 0.53 & 0.034 \\
\hline 23478-PeCDF & 0.67 & 0.25 \\
\hline 123478-HxCDF & 0.52 & 0.053 \\
\hline 123678-HxCDF & 0.82 & 0.059 \\
\hline 123789-HxCDF & 0.81 & 0.041 \\
\hline 234678-HxCDF & 0.56 & 0.086 \\
\hline 1234678-HpCDF & 0.19 & 0.009 \\
\hline 1234789-HpCDF & 0.052 & 0.008 \\
\hline OCDF & 0.066 & 0.002 \\
\hline
\end{tabular}

Mass Spectrom. Lett. 2011 Vol. 2, No. 1, 12-15 
the LLE method. The MDL with the SPE method and a 7-L sample was one-tenth the MDL with the LLE method and a 0.5 -L sample.

\section{Waste water analysis}

The extraction efficiencies of the semi-automated SPE system and the LLE system were comparable for spiked deionized water samples. The optimized SPE method was used to analyze two real waste water samples from industrial effluent. Tables 3 and 4 compare the recoveries and concentrations obtained from the two waste water samples using the SPE and LLE methods, respectively. The recoveries of ${ }^{13} \mathrm{C}$-labeled compounds were in the range of $56-83 \%$ for waste water sample A and $60-87 \%$ for waste water sample B, which met the Environmental Protection Agency (EPA) $1613^{19}$ and JIS K $0312^{18}$ criteria. There were no significant differences in the recoveries between the LLE and SPE methods, and the concentrations of the detected congeners determined with both methods were similar. However, because the MDLs were lower with SPE than with LLE, the concentrations of four congeners (1234678-HpCDD, 2378-TeCDF, 23478-PeCDF, and $123789-\mathrm{HxCDF}$ ) that were not detected with the LLE

Table 3. The measurement results, including recovery, for waste water sample A.

\begin{tabular}{|c|c|c|c|c|}
\hline \multirow[t]{2}{*}{ Congeners } & \multicolumn{2}{|c|}{$\begin{array}{l}\text { Concentration } \\
\text { (pg I-TEQ/L) }\end{array}$} & \multicolumn{2}{|c|}{ Recovery (\%) } \\
\hline & $0.5 \mathrm{~L}$ (LLE) & L (SPE) & $\mathrm{L}(\mathrm{LI}$ & $(\mathrm{SPE})$ \\
\hline 2378-TeCDD & $<3.5$ & $<0.18$ & 102 & 69 \\
\hline 12378-PeCDD & $<4.1$ & $<0.14$ & 105 & 83 \\
\hline 123478-HxCDD & $<0.65$ & $<0.10$ & 110 & 83 \\
\hline 123678-HxCDD & $<0.88$ & $<0.06$ & 90 & 69 \\
\hline 123789-HxCDD & $<0.71$ & $<0.10$ & 100 & 76 \\
\hline 1234678-HpCDD & $<0.13$ & 0.09 & 84 & 65 \\
\hline OCDD & 0.07 & 0.06 & 66 & 56 \\
\hline 2378-TeCDF & $<0.35$ & 0.25 & 94 & 68 \\
\hline 12378-PeCDF & 0.16 & 0.13 & 96 & 72 \\
\hline 23478-PeCDF & $<0.67$ & 0.72 & 107 & 82 \\
\hline 123478-HxCDF & 1.08 & 0.96 & 96 & 71 \\
\hline 123678-HxCDF & 0.84 & 0.73 & 99 & 73 \\
\hline 123789-HxCDF & $<0.81$ & 0.05 & 88 & 63 \\
\hline 234678-HxCDF & 0.88 & 0.80 & 94 & 70 \\
\hline 1234678-HpCDF & 2.45 & 2.45 & 85 & 66 \\
\hline 1234789-HpCDF & 0.35 & 0.30 & 84 & 65 \\
\hline OCDF & 11.04 & 11.84 & & \\
\hline Total & 16.86 & 18.38 & & \\
\hline
\end{tabular}

Table 4. The measurement results, including recovery, for waste water sample B.

\begin{tabular}{ccccc}
\hline \hline \multirow{2}{*}{ Congeners } & \multicolumn{2}{c}{$\begin{array}{c}\text { Concentration } \\
\text { (pg I-TEQ/L) }\end{array}$} & \multicolumn{2}{c}{ Recovery $(\%)$} \\
\cline { 2 - 5 } & 0.5 L (LLE) 7 L (SPE) 0.5 L (LLE) 7 L (SPE) \\
\hline 2378-TeCDD & $<3.5$ & $<0.18$ & 71 & 77 \\
12378-PeCDD & $<4.1$ & $<0.14$ & 73 & 84 \\
123478-HxCDD & $<0.65$ & $<0.10$ & 77 & 87 \\
123678-HxCDD & $<0.88$ & $<0.06$ & 64 & 74 \\
123789-HxCDD & $<0.71$ & $<0.10$ & 71 & 81 \\
1234678-HpCDD & $<0.13$ & $<0.02$ & 67 & 71 \\
OCDD & $<0.02$ & 0.01 & 60 & 60 \\
2378-TeCDF & $<0.35$ & $<0.02$ & 71 & 83 \\
12378-PeCDF & $<0.53$ & $<0.03$ & 72 & 84 \\
23478-PeCDF & $<0.67$ & $<0.25$ & 75 & 87 \\
123478-HxCDF & $<0.52$ & 0.69 & 69 & 78 \\
123678-HxCDF & $<0.82$ & 0.53 & 69 & 80 \\
123789-HxCDF & $<0.81$ & $<0.04$ & 73 & 76 \\
234678-HxCDF & $<0.58$ & 0.49 & 72 & 79 \\
1234678-HpCDF & 3.85 & 3.01 & 70 & 73 \\
1234789-HpCDF & $<0.05$ & 0.19 & 67 & 69 \\
\hline OCDF & 3.72 & 3.53 & & \\
\hline Total & 7.58 & 8.46 & & \\
\hline
\end{tabular}

method could be quantified using the disk-type SPE method for waste water sample A. The 1234678-HpCDD in waste water sample A was quantified with the SPE method (concentration $0.09 \mathrm{pg}$ I-TEQ/L), whereas it was not detected with the LLE method because the MDL for 1234678-HpCDD with the LLE method $(0.13$ pg I-TEQ/L) was higher than its concentration. Similarly, for waste water sample B, five more congeners (OCDD, 123478-HxCDF, 123678-HxCDF, 234678-HxCDF, and 1234789-HpCDF) were quantified using SPE method.

If the LLE method was used for 7-L sample preparation to meet the detection limit, extraction should be repeated several times. It requires a lot of time and large amounts of organic solvents, which lead to low recoveries. The SPE method enabled continuous filtration with semi-automation and served as an improved absorption system for monitoring PCDD/Fs in aqueous samples with high recoveries and easy operation. This method was validated up to 40 -L sample previously ${ }^{16}$ and the recoveries were in the range of $62 \sim 95 \%$. However, in the case of waste water including a lot of suspended solid, it took longer time to extract since the GFF was clogged. To solve clogging trouble, it will be necessary to apply another type of filters, which is an area still under study. 


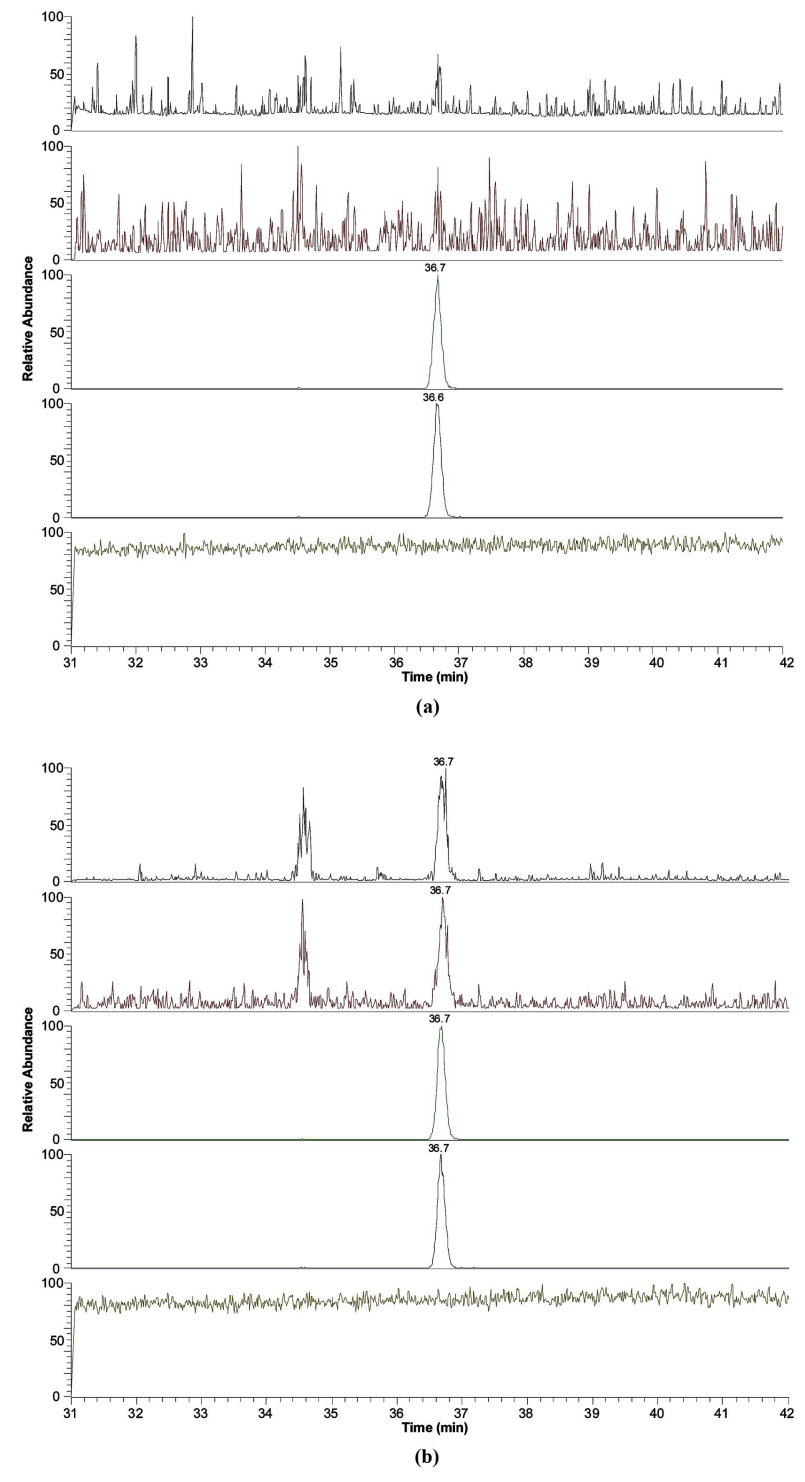

Figure 1. Chromatograms of $1234678-\mathrm{HpCDD}$ in waste water sample A extracted by LLE (a) and SPE methods (b).

\section{Conclusions}

In this study, 7-L waste water samples were extracted using a C18 disk with a 90-mm i.d., and 0.5-L samples were extracted using liquid-liquid extraction. A comparison of the extraction efficiencies between the semi-automated SPE system and the LLE system revealed no significant differences in recoveries between the two methods. The MDLs of the SPE method were less than one-tenth the MDLs of the LLE method, allowing several congeners undetectable with LLE to be quantified using the disk-type SPE method. The semi-automated disk-type SPE system is an appropriate method for analyzing sub-ppq levels of PCDD/Fs in waste water samples with high recoveries and easy operation.

\section{Acknowledgments}

This work was supported by LG Chem research funds.

\section{References}

1. Huff, J. E.; Moore, J. A.; Saracci R. Tomatis L. Environ. Health Perspect. 1980, 36, 221.

2. Poland, A.; Knutson, J. C. Annu. Rev. Pharmacol. Toxicol. 1982, 22, 517.

3. Pohjanvirta, R.; Tuomisto, J. Pharmacol. Rev. 1994, 46, 483.

4. Birnbaum, L. S.; Tuomisto, J. J. Food Addit. Contam. 2000, 17, 275.

5. Alaluusua, S.; Calderara, P.; Gerthoux, P. M.; Lukinmaa, P. L.; Kovero, O.; Needham, L.; Patterson, D. G.; Tuomisto, J.; Mocarelli, P. Environ. Health Perspect. 2004, 112, 1313.

6. Steenland, K.; Bertazzi, P.; Baccarelli, A.; Kogevinas, M. Environ. Health Perspect. 2004, 112, 1265.

7. Hester, R. E.; Harrison, R. M. Chlorinated organic micropollutants, The Royal Society of Chemistry: Cambridge, 1996.

8. Gribble, G.W. Environ. Sci. Technol. 1994, 28, 310A.

9. Hashimoto, S.; Wakimoto, T.; Tatsukawa, R. Chemosphere 1990, 21, 825 .

10. Ministry of Environment, Republic of Korea (MOE), Persistent Organic Pollutant Special Management Law, 2008.

11. Meyer, C.; O'Keeffe, P.; Hilker, D.; Rafferty, L.; Wilson, L.; Connor, S.; Aldous, K.; Markussen, K.; Slade, K. Chemosphere 1989, 19, 21.

12. Rappe, C.; Kjeller, L. O.; Andersson, L. Chemosphere 1989, 19, 13.

13. Campoy, C.; Jimenez, M.; Olea-Serrano, M. F.; Frias, M. M.; Canabate, F.; Olea, N.; Bayes, R.; Molina-Font, J. A. Ear. Hu. Dev. 2001, 65, S183.

14. Jeannot, R.; Sabik, H.; Sauvard, E.; Genin, E. J. J. Chromatogr. A 2000, 879, 51.

15. Pujadas, E.; Diaz-Ferrero, J.; Marti, R.; Broto-Puig, F.; Comellas, L.; Rodriguez-Larena, M. C. Chemosphere 2001, 43, 449.

16. Choi, J. W.; Lee, J. H.; Moon, B. S.; Baek, K. H. J. Chromatogr. A 2007, 1157, 17.

17. North Atlantic Treaty Organization, Committee on the Challenges of Modern Society (NATO/CCMS), 1988, Report Number 176.

18. JIS K0312, Method for determination of tetra- through octa-chlorodibenzo-p-dioxins, tetra- through octachlorodibenzofurans and coplanar polychlorobiphenyls in industrial water and waste water, Japanese Industrial Standards Committee (JIS), Tokyo, Japan, 2005.

19. EPA Method 1613, Tetra- through octachlorinated dioxins and furans by isotopic dilution HRGC-HRMS, US Environmental Protection Agency (EPA), Washington, D.C., 1994. 